Pacific Journal of Mathematic 


\title{
TAUTNESS FOR ALEXANDER-SPANIER COHOMOLOGY
}

\author{
E. H. SPANIER
}

The purpose of this note is to give a straightforward unified proof of the tautness of Alexander-Spanier cohomology in the cases where it is known to be valid and to give a necessary condition that every closed (arbitrary) subspace be taut with respect to zero dimensional cohomology.

Let $F$ denote a contravariant functor from the category of topological spaces to the category of abelian groups. A subspace $A$ of a topological space $X$ is said to be taut with respect to $F$ if the canonical map $\lim _{\rightarrow}\{F(U)\} \rightarrow F(A)$ is an isomorphism (the direct limit is taken over the family of all neighborhoods of $A$ in $X$, the family being directed downward by inclusion). The subspace $A$ is taut in $X$ if it is taut with respect to the Alexander-Spanier cohomology theory $\bar{H}$ for every dimension and every coefficient group (for notation and termintology dealing with $\bar{H}$ see [6]).

This concept of tautness has proved to be important. In [6] and [7] it is shown that a closed subspace of a paracompact Hausdorff space is taut, and this is used to deduce a strong excision property for $\bar{H}$. This tautness property is also used in [6] to derive the continuity property for $\bar{H}$. In [4] it is shown that an arbitrary subspace of a metric space is taut with respect to Cech cohomology, and this is used to obtain a general duality in spheres. Since the Cech cohomology is isomorphic to $\bar{H}$ [3], every subspace of a metric space is taut. In [2] it is shown that every neighborhood retract of $X$ is taut in $X$, and this is used to prove a generalized homotopy property for compact spaces. In [1] tautness is considered for sheaf cohomology and used in proving the Vietoris-Begle mapping theorem.

We shall prove a simple lemma which gives a sufficient condition for tautness. This sufficient condition is enough to establish tautness in all the various cases where it is known.

Let $U$ be a collection of subsets of $X$ and $A$ a subset of $X$. The star of $A$ with respect to $U$, denoted by $\operatorname{st}(A, \mathcal{U})$, is defined to be the union of those elements of $U$ whose intersection with $A$ is nonempty. An open covering of $A$ in $X$ is a collection $U$ of open sets of $X$ such that $A \subset \operatorname{st}(A, \mathcal{U})$.

The following seems to be the main fact underlying tautness (see [2] and [6]). 
Lemma. Let $A$ be a subspace of $X$ and suppose that for every open covering $\mathcal{U}$ of $A$ in $X$ there are an open covering $\mathscr{V}$ of $A$ in $X$ and a function (not necessarily continuous) $f: \operatorname{st}(A, \mathscr{V}) \rightarrow A$ such that $:$

(1) $f(a)=a$ for all $a \in A$.

(2) For each $V \in \mathscr{V}$ with $V \cap A \neq \varnothing$ there is $U \in \mathscr{U}$ such that $V \cup f(V) \subset U$.

Then $A$ is taut in $X$.

Proof. (Recall the notation is as in [6].) An arbitrary qdimensional cohomology class of $A$ is represented by a $q$-cochain $\varphi \in C^{q}(A)$ such that $\delta \varphi=0$ on $\mathcal{U}^{q+2} \cap A^{q+2}$ where $\mathcal{U}$ is an open covering of $A$ in $X$. Choose $\mathscr{V}$ and $f$ with respect to this $\mathcal{U}$ to satisfy (1) and (2). Then $f^{*} \varphi \in C^{q}(\operatorname{st}(A, \mathscr{V}))$ is a $q$-cochain such that $\delta f^{*} \varphi=f^{*} \delta \varphi$, and, by (2), the latter vanishes on $\{V \in \mathscr{V} \mid V \cap A \neq \varnothing\}^{q+2}$. Thus, $f^{*} \varphi$ represents an element of $\bar{H}^{q}(\operatorname{st}(A, \mathscr{V}))$, and, by (1), its restriction to $A$ is the element of $\bar{H}^{q}(A)$ represented by $\varphi$. Therefore, the canonical map $\lim _{\rightarrow}\left\{\bar{H}^{q}(U)\right\} \rightarrow \bar{H}^{q}(A)$ is an epimorphism.

Let $U$ be a neighborhood of $A$. An element of $\bar{H}^{a}(U)$ whose restriction to $A$ is 0 is represented by a $q$-cochain $\varphi \in C^{q}(U)$ such that $\delta \varphi=0$ on $U_{1}^{q+2}$ where $U_{1}$ is an open covering of $U$ and such that there is a $(q-1)$-cochain $\varphi^{\prime} \in C^{q-1}(A)$ with $\varphi \mid A=\delta \varphi^{\prime}$ on $U_{2}^{q+1} \cap A^{q+1}$ where $\mathcal{U}_{2}$ is an open covering of $A$ in $X$. Let $\mathcal{U}=\left\{U_{1} \cap U_{2} \mid U_{1} \in \mathcal{U}_{1}\right.$ and $\left.U_{2} \in \mathcal{U}_{2}\right\}$. Then $\mathcal{U}$ is an open covering of $A$ in $X$ such that $\delta \varphi=0$ on $\mathcal{U}^{q+2}$ and $\varphi \mid A=\delta \varphi^{\prime}$ on $\mathcal{U}^{q+1} \cap A^{q+1}$. Let $\mathscr{V}$ and $f$ satisfy (1) and (2) with respect to this $U$. It follows from (1) and (2) using the Fundamental Lemma 9.1 of [5] that $\varphi \mid \operatorname{st}(A, \mathscr{V})$ and $f^{*}(\varphi \mid A)$ represent the same element of $\bar{H}^{q}(\operatorname{st}(A, \mathscr{V}))$. Since $f^{*}(\varphi \mid A)=f^{*} \delta \varphi^{\prime}=\delta f^{*} \varphi^{\prime}$ on $\{V \in \mathscr{V} \mid V \cap A \neq \varnothing\}^{a+1}$, we see that $f^{*}(\varphi \mid A)$ represents 0 in $\bar{H}^{q}(\operatorname{st}(A, \mathscr{V}))$. Therefore, $\varphi \mid \operatorname{st}(A, \mathscr{V})$ represents 0 in $\bar{H}^{q}(\operatorname{st}(A, \mathscr{V}))$, and the canonical map $\lim _{\rightarrow}\left\{\bar{H}^{a}(U)\right\} \rightarrow \bar{H}^{a}(A)$ is a monomorphism.

THEOREM 1. In each of the following cases $A$ is taut in $X$.

(1) $A$ is compact and $X$ is Hausdorff.

(2) $A$ is closed and $X$ is paracompact Hausdorf.

(3) $A$ is arbitrary and every open subset of $X$ is paracompact Hausdorff.

(4) $A$ is a neighborhood retract of $X$.

Proof. In each of the first three cases it is easy to verify that if $\mathcal{U}$ is any open covering of $A$ in $X$ there is an open covering $\mathscr{V}$ of $A$ in $X$ such that the collection $\{\operatorname{st}(V, \mathscr{V}) \mid V \in \mathscr{V}$ and $V \cap A \neq \varnothing\}$ is a refinement of $\mathcal{U}$. If $f: \operatorname{st}(A, \mathscr{V}) \rightarrow A$ is defined so that $f(a)=a$ for $a \in A$ and so that for every $x \in \operatorname{st}(A, \mathscr{V})$ there is $V^{\prime} \in \mathscr{V}$ with $x$ and $f(x)$ both in $V^{\prime}$, then $\mathscr{V}$ 
and $f$ satisfy (1) and (2) of the Lemma with respect to $U$ (see Lemma 1 on p. 316 of [6]). Therefore, $A$ is taut in $X$.

In the fourth case let $r: N \rightarrow A$ be a retraction of an open neighborhood $N$ of $A$ to $A$. If $U$ is an open covering of $A$ in $X$ let $\mathscr{V}=\left\{U \cap r^{-1}(U \cap A) \mid U \in \mathcal{U}\right\}$. Then $\mathscr{V}$ is an open covering of $A$ in $X$. Define $f: \operatorname{st}(A, \mathscr{V}) \rightarrow A$ by $f=r \mid \operatorname{st}(A, \mathscr{V})$. Then $\mathscr{V}$ and $f$ satisfy (1) and (2) of the Lemma with respect to $U$ and so $A$ is taut in $X$.

The following result is a necessary condition for tautness of every closed (arbitrary) subspace with respect to $\bar{H}^{0}$. It can be used to provide examples where tautness fails to hold.

THEOREM 2. If $X$ is a space such that every closed (arbitrary) subspace is taut with respect to $\bar{H}^{0}$, then $X$ is normal (completely normal).

Proof. We present the proof in the completely normal case, the normal case being analogous. To show $X$ is completely normal it suffices to show that if $E$ and $F$ are subsets of $X$ such that $\bar{E} \cap F=\varnothing=$ $E \cap \bar{F}$ then $E$ and $F$ can be separated by open sets in $X$. Given such $E$ and $F$ let $A=E \cup F$. Then $A$ is a subspace of $X$ and $E$ and $F$ are both open and closed in $A$. Let $\varphi$ be the 0-cocycle on $A$ which is 0 on $E$ and 1 on $F$. Assuming $A$ is taut in $X$, there is an open neighborhood $W$ of $A$ in $X$ and a 0 -cocycle $\psi$ on $W$ such that $\psi \mid A=\varphi$. Since a 0 -cocycle is a locally constant function, $U=\{x \in W \mid \psi(x)=0\}$ and $V=$ $\{x \in W \mid \psi(x)=1\}$ are disjoint open sets in $W$, hence in $X$, which separate $E$ and $F$.

\section{REFERENCES}

1. G. E. Bredon, Sheaf Theory, McGraw-Hill Book Company, Inc., New York, 1967.

2. Satya Deo, On the tautness property of Alexander-Spanier cohomology, Proc. Amer. Math. Soc., 52 (1975), 441-444.

3. C. H. Dowker, Homology groups of relations, Ann. of Math., (2) 56 (1952), 84-95.

4. K. Sitnikov, Combinatorial topology of nonclosed sets $I$. The first duality law; spectral duality, Mat. Sb. N. S. 34 (76) (1954), 3-54 (Russian). Amer. Math. Soc. Transl. (2) 15 (1960), 245-295.

5. E. H. Spanier, Cohomology theory for general spaces, Ann. of Math., (2) 49 (1948), 407-427.

6. - Algebraic Topology, McGraw-Hill Book Company, Inc., New York, 1966.

7. A. D. Wallace, The map excision theorem, Duke Math. J., 19 (1952), 177-182.

Received May 6, 1977.

UNIVERSiTy OF CALIFORNIA

BERKELEY, CA 94720 



\section{PACIFIC JOURNAL OF MATHEMATICS}

\section{EDITORS}

RICHARD ARENS (Managing Editor)

University of California

Los Angeles, CA 90024

R. A. BeAumont

University of Washington

Seattle, WA 98105

C. C. MOORE

University of California

Berkeley, CA 94720
J. DUGUNDJI

Department of Mathematics

University of Southern California

Los Angeles, CA 90007

R. FINN AND J. MILGRAM

Stanford University

Stanford, CA 94305

\section{ASSOCIATE EDITORS}
E. F. BECKENBACH
B. H. NEUMANN
F. WOLF
K. YoshidA

\section{SUPPORTING INSTITUTIONS}

UNIVERSITY OF BRITISH COLUMBIA

UNIVERSITY OF SOUTHERN CALIFORNIA

CALIFORNIA INSTITUTE OF TECHNOLOGY

STANFORD UNIVERSITY

UNIVERSITY OF CALIFORNIA

UNIVERSITY OF HAWAII

MONTANA STATE UNIVERSITY

UNIVERSITY OF TOKYO

UNIVERSITY OF NEVADA

UNIVERSITY OF UTAH

NEW MEXICO STATE UNIVERSITY

OREGON STATE UNIVERSITY

UNIVERSITY OF OREGON

OSAKA UNIVERSITY

WASHINGTON STATE UNIVERSITY

UNIVERSITY OF WASHINGTON

AMERICAN MATHEMATICAL SOCIETY

The Supporting Institutions listed above contribute to the cost of publication of this Journal, but they are not owners or publishers and have no responsibility for its contents or policies.

Mathematical papers intended for publication in the Pacific Journal of Mathematics should be in typed form or offset-reproduced (not dittoed), double spaced with large margins. Underline Greek letters in red, German in green, and script in blue. The first paragraph or two must be capable of being used separately as a synopsis of the entire paper. Items of the bibliography should not be cited there unless absolutely necessary, in which case they must be identified by author and Journal, rather than by item number. Manuscripts, in duplicate, may be sent to any one of the four editors. Please classify according to the scheme of Math. Reviews, Index to Vol. 39. All other communications should be addressed to the managing editor, or Elaine Barth, University of California, Los Angeles, California, 90024.

100 reprints are provided free for each article, only if page charges have been substantially paid. Additional copies may be obtained at cost in multiples of 50 .

The Pacific Journal of Mathematics is issued monthly as of January 1966. Regular subscription rate: $\$ 72.00$ a year (6 Vols., 12 issues). Special rate: $\$ 36.00$ a year to individual members of supporting institutions.

Subscriptions, orders for numbers issued in the last three calendar years, and changes of address should be sent to Pacific Journal of Mathematics, 103 Highland Boulevard, Berkeley, California, 94708.

PUBLISHED BY PACIFIC JOURNAL OF MATHEMATICS, A NON-PROFIT CORPORATION

Printed at Jerusalem Academic Press, POB 2390, Jerusalem, Israel. 


\section{Pacific Journal of Mathematics}

\section{Vol. 75, No. $2 \quad$ October, 1978}

Susan Jane Zimmerman Andima and W. J. Thron, Order-induced

topological properties ................................... 297

Gregory Wade Bell, Cohomology of degree 1 and 2 of the Suzuki groups . . 319

Richard Body and Roy Rene Douglas, Rational homotopy and unique

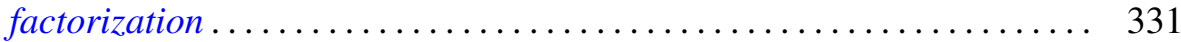

Frank Lewis Capobianco, Fixed sets of involutions ................. 339

L. Carlitz, Some theorems on generalized Dedekind-Rademacher sums .... 347

Mary Rodriguez Embry and Alan Leslie Lambert, The structure of a special class of weighted translation semigroups .....................

Steve Ferry, Strongly regular mappings with compact ANR fibers are

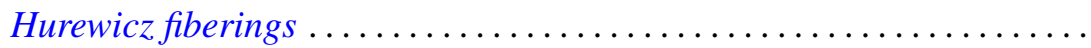

Ivan Filippenko and Marvin David Marcus, On the unitary invariance of the

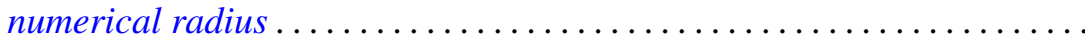

$\mathrm{H}$. Groemer, On the extension of additive functionals on classes of convex

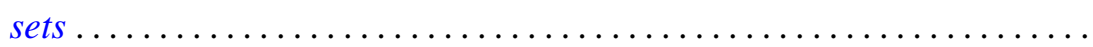

Rita Hall, On the cohomology of Kuga's fiber variety ............... 411

H. B. Hamilton, Congruences on $\mathrm{N}$-semigroups ................. 423

Manfred Herrmann and Rolf Schmidt, Regular sequences and lifting

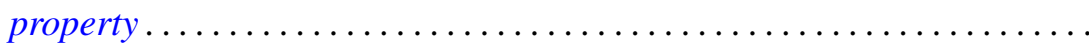

James Edgar Keesling, Decompositions of the Stone-Čech compactification which are shape equivalences .....................

Michael Jay Klass and Lawrence Edward Myers, On stopping rules and the expected supremum of $S_{n} / T_{n}$

Ronald Charles Linton, $\lambda$-large subgroups of $C_{\lambda}$-groups

William Owen Murray, IV and L. Bruce Treybig, Triangulations with the free cell property ............................

Louis Jackson Ratliff, Jr., Polynomial rings and $H_{i}$-local rings ...

Michael Rich, On alternate rings and their attached Jordan rings....

Gary Sampson and H. Tuy, Fourier transforms and their Lipschitz

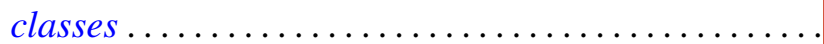

Helga Schirmer, Effluent and noneffluent fixed points on dendrites ...

Daniel Byron Shapiro, Intersections of the space of skew-symmetric maps

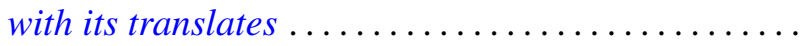

Edwin Spanier, Tautness for Alexander-Spanier cohomology ...

Alan Stein and Ivan Ernest Stux, A mean value theorem for binary digits ...

Franklin D. Tall, Normal subspaces of the density topology . .

William Yslas Vélez, Prime ideal decomposition in $F\left(\mu^{1 / p}\right) \ldots$ 